\title{
Validation of Jason and Envisat Altimeter Dual Frequency Rain Flags
}

\author{
Jean TOURNADRE
}

Laboratoire d'Océanographie Spatiale, Institut Français de Recherche pour l'Exploitation de la Mer, Plouzané, France

*: Corresponding author : Tél.: (33) 2982244 97, e-mail: jean.tournadre@ifremer.fr

\begin{abstract}
:
New rain flags based on the dual frequency capabilities of the new Jason Poseidon-2 and Envisat RA2 altimeters have been tested, developed and adopted for the operational processing of the altimeter data. Their validation conducted during the calibration/validation phases of the satellites is presented here. The Jason flag is validated by comparison with the TOPEX one, using the Tandem mission. The results show a very good agreement between the two sensors and the two rain flags The Envisat flag is validated by comparison with both Jason and TOPEX using global and collocated data sets. The results show similar performances for the three sensors. The f relations estimated during the calibration-validation period and presented here have been given to the altimeter ground processing facilities for operational use.
\end{abstract}

Keywords: Jason, Envisat, Topex, Altimeters, Rain Flag, Dual Frequency 


\section{INTRODUCTION}

Past experiences with ERS and Topex/Poseidon altimeter data have shown that rain can significantly alter the quality of altimeter measurements (dynamic heights, significant wave heights, wind speed) (Guymer et al., 1995, Tournadre and Morland, 1997, Quartly et al, 1996, Tournadre, 1998). Among all the different atmospheric phenomena that can affect the altimeter data, rain is certainly one of the less well understood and at present no reliable correction can be made for the whole range of geophysical parameters. For ocean circulation and climate studies, it is thus of prime importance to eliminate data that might possibly be affected by rain. Until now, the rain-contaminated data have been simply discarded using a flag set using concurrent passive microwave radiometer measurements. These passive microwave data are also used to calculate the atmospheric water vapour correction to the dynamic height and to give an estimate of atmospheric liquid water (Ruf et al., 1995).

The dual frequency capability of the Topex altimeter (NRA) has led to the definition of a new rain flag (Tornadoes and Morland, 1998, Quartly et al, 1996). The attenuation of electromagnetic signal by rain is indeed frequency dependent and the detection of departures from a normal or "rain free" relationship between the two frequencies backscatter measurements can be used to detect rain events. This kind of rain flag based on the altimeter measurement itself has been shown to perform better than the one based on coincident passive microwave data. Following these studies which successfully applied a dual frequency altimeter rain flag to the Topex altimeter data, dual frequency rain flags have been proposed, developed and adopted for both Jason Poseidon-2 and Envisat RA-2 altimeters (Tournadre et al, 2000).

Prior to the launch of the satellites, rain free relationships were given to the operational centres to be included in the processing chain of the altimeter data. As the altimeter backscatter measurements are not calibrated to the precision required for rain flagging, it was expected that these relationship would not perform satisfactorily. The calibration-validation period of the two satellites was used to tune the relations and to validate the rain flagging 
process. Six months of Jason data and 3 months of Envisat data have been used for this validation. Following this study, new relations were given to the processing facilities for operational use. The present paper describes the validation of both rain flags.

In the section 2 , the two altimeters are briefly described. The dual rain flag altimeter principle as well as the method of validation is presented in section 3. Section 4 presents the validation of backscatter measurements and of the « rain free » relation. The rain flagging results are presented in section 5 . The final validation by comparison with rain climatology is presented in section 6 .

\section{THE ENVISAT AND JASON ALTIMETERS}

\subsection{Jason}

The Jason satellite was launched on December $7^{\text {th }}$, 2001. It carries the Poseidon- 2 altimeter, which is derived from the experimental Poseidon-1 altimeter on Topex/Poseidon. It is a compact, low-power, low mass instrument offering a high degree of reliability. Poseidon-2 is a dual frequency radar altimeter that emits pulses at $13.6 \mathrm{GHz}(\mathrm{Ku}$ band) and $5.3 \mathrm{GHz}(\mathrm{C}$ band). The second frequency is used to determine electron content in the atmosphere and analyses the return signal reflected by the surface. The signal round-trip time is estimated very precisely to calculate the range, after applying corrections. A detailed description of the Poseidon-2 altimeter is given in Ménard and $F u$ (2001).

\subsection{Envisat}

The RA-2, Radar Altimeter of second generation, of the Envisat satellite, launched on March 1 2002, is derived from the ERS-1 and 2, RA, altimeters, providing improved measurements and capabilities (Resti et al., 1999, Benveniste et al., 2001). In particular, it operates not only at $\mathrm{Ku}$ band $(13.575 \mathrm{GHz})$ like the RA but also at $\mathrm{S}$ band $(3.2 \mathrm{GHz})$. As for Poseidon, this secondary channel is used to determine the electron content of the atmosphere and thus to compensate the range error on altitude caused by the propagation of the radar signal through the ionosphere. 


\section{DESCRIPTION OF THE DUAL FREQUENCY ALTIMETER RAIN FLAG}

\subsection{Principle}

The rain flag principle is identical for both satellite and is similar to the one presented by Tournadre and Morland (1997) and Quartly et al. (1996) for the Topex altimeter. It is only briefly summarized in the present paper. A more detailed description is given in the above references and in Tournadre et al. (2000).

The main impact of rain on electro-magnetic signals at $\mathrm{Ku}, \mathrm{C}$ and $\mathrm{S}$ band is attenuation. Scattering and modification of sea surface roughness can be considered as negligible in a first order approximation. Attenuation is frequency dependant and is one (two) of order(s) of magnitude larger at $\mathrm{Ku}$ band that at C (S) band (Ulaby et al., 1981). Except for heavy rain ( $>20 \mathrm{~mm} / \mathrm{hr}$ ), for which the $\mathrm{Ku}$ band signal is attenuated by $10 \mathrm{~dB}$, the $\mathrm{C}$ band signal can be considered as unaffected by rain. The $\mathrm{S}$ band signal is almost never affected, except within Tropical cyclone rain systems. Using this frequency dependence of the attenuation by rain, the rain flag is based on the detection of occurrences for which the $\sigma_{0}$ measured at $\mathrm{Ku}$ band is significantly attenuated compared to the measured $\mathrm{C} / \mathrm{S}$ band $\sigma_{0}$. In practice, the measured $\mathrm{Ku}$ band $\sigma_{0}$ is compared to the $\mathrm{Ku}$ band $\sigma_{0}$ expected from the measured $\mathrm{C}(\mathrm{S})$ band $\sigma_{0}$ value, i.e.

$$
\sigma_{0}=\sigma_{0}^{K u}-f\left(\sigma_{c}^{C / S}\right)<A(\mathbf{1})
$$

where $f$ is the $\mathrm{Ku} / \mathrm{C}(\mathrm{S})$ band "rain free" or "wind only" relationship and $A$ is an attenuation threshold. It should be noted that in general the Geophysical Data Record $\sigma_{0}$ 's are corrected for atmospheric water vapour attenuation. As this correction includes cloud liquid water effects, and thus at least partially compensates for the rain effects, it should be removed for rain flagging. The "rain free" $f$ relationship is determined from the actual dual frequency altimeter measurements.

To take into account the geophysical variability of $\sigma_{0}$, which becomes large at low wind speed (high $\sigma_{0}$ ) the best threshold $A$ is 2 times the rms of the $f$ relation, $r m s\left(\sigma_{0}{ }^{C}\right.$ ) (Tournadre and Morland, 1997). To minimize the possibility of false alarms, especially at low wind 
speeds, it is necessary to test also the presence of liquid water within the atmosphere. This is done by testing the passive radiometer (Jason Microwave Radiometer, JMR, Topex Microwave Radiometer, TMR, and Envisat Microwave Radiometer, MWR) cloud liquid water estimate $\left(L_{z}\right)$

$$
L_{Z}<L_{Z_{0}}(\mathbf{2})
$$

where $L_{Z_{0}}$ is a threshold fixed to $200 \mu \mathrm{m}$.

The use of $\mathrm{S}$ band instead of $\mathrm{C}$ band for the Envisat altimeter does not significantly modify the flagging process because the $\mathrm{S}$ band is even more insensitive to rain than the $\mathrm{C}$ band (Tournadre et al., 2000).

\subsection{Method of validation}

The rain flagging is based on well-known physics, i.e., the attenuation of electromagnetic signals by raindrops for which the literature is plentiful since the 1940's. It has been successfully tested and validated for the Topex data. Its main purpose is to eliminate all the data that can be affected by precipitation and thus lead to erroneous estimates of geophysical parameters from further processing whilst keeping a low rate of false alarm. It relies on a good estimate of the $f$ relation. Prior to launch, $f$ relations were given to the processing facilities. The Jason one was computed using 100 cycles (i.e. 1000 days of data) of Topex Ku and $\mathrm{C}$ band $\sigma_{0}$ data. For Envisat, as no $\mathrm{S}$ band data existed, a theoretical relation was computed in the following way (Tournadre and Quartly, 2003). For wind speeds between 2 and $30 \mathrm{~m} / \mathrm{s}$ the sea surface spectrum was computed using the Elfouhaily et al. (1997) model. The spectrum was then integrated to compute the mean surface square slope (mss). The mss was then converted to backscatter coefficient. For a given wind speed, the rms of the relation was the one estimated for the corresponding Topex $\mathrm{Ku} / \mathrm{C}$ band relation.

The calibration-validation periods of the satellites has been used to estimate specific $f$ relations, to test the performances of the rain flag and to validate the rain flagging process.

For Jason, it can be easily done by comparison with Topex data. From January 15, 2002 to August 25, 2002, both satellites were put on the same ground track, Jason-1 leading 
Topex/Poseidon by $1 \mathrm{~min}$. This constitutes the tandem mission, designed to ensure that Jason-1 will continue seamlessly adding to the nine years of TOPEX/Poseidon data, and for as long as TOPEX/Poseidon remains in good health, increasing our global coverage of data twofold. Seven months of coincident and collocated data (Jason cycles 2 to 22) are thus available to cross-calibrate the satellite instruments as well as geophysical parameters and flags, among them the rain flag.

For Envisat, such an extensive cross-calibration data set is not available. However, a cross validation with Jason and Topex is possible using both collocated and global data sets for November and December 2002. The October 2002 data could not be used because of the altimeter experienced some saturation problems, which lead to erroneous $S$ band $\sigma_{0}$ data. It should also be noted that the Microwave Radiometer experienced a series of problems that lead to the absence of liquid water content estimates for several days.

In a first validation step, the compatibility of the backscatter measurements between the different altimeters is thoroughly checked. This is done by statistical comparison of the $\sigma_{0}$ data (collocated or not). The $f$ relation and its rms are then estimated for the three altimeters and intercompared. After that, the flagging procedure is applied to each data set and the flagged samples data set are analysed and compared. As a final validation, the probability of rain as determined from the dual frequency altimeter data is compared to rain climatology data.

\section{VALIDATION AND ESTIMATE OF THE $F$ RELATION}

\subsection{Data screening}

The $f$ relation should represent a "rain free" (or wind only) relation between $\mathrm{Ku}$ and $\mathrm{C}(\mathrm{S})$ band $\sigma_{0}$. The key point in defining such a wind only relationship is to include as many data points as possible, encompassing a wide range of wind speeds and geographical regions, but not including any points likely to be affected by rain, sea-ice, land-contamination or instrumental problems. The data are thus carefully screened using the following criteria for both altimeter measurements 
flags: land flags and microwave radiometers measurements set to ocean. Instruments flags set to nominal functioning. Ice flag set to no ice;

Geophysical values: backscatter measurements $(\mathrm{Ku} / \mathrm{C}, \mathrm{Ku} / \mathrm{S})$ positive. Atmospheric corrections less than $1 \mathrm{~dB}$. Microwave liquid water content less than $600 \mu \mathrm{m}$ (threshold used to flag rain on Topex). Off-nadir angle estimated from the echo waveform analysis is less than $0.04 \mathrm{deg}^{2}$. Latitude between $50^{\circ} \mathrm{S}$ and $50^{\circ} \mathrm{N}$.

\subsection{Backscatter measurements}

Following the user's manuals, GDRs (SSALTO, 1999, Envisat RA2/MWR, 2001) $\sigma_{0}$ measurements are estimated as follows:

$$
\sigma_{0}^{G D R}=\sigma_{0}^{\text {meas }}+\Delta \sigma_{0}^{i n s t r}+\Delta \sigma_{0}^{\text {atmos }}
$$

where $\sigma_{0}^{\text {meas }}$ is the measured backscatter coefficient, $\Delta \sigma_{0}^{i n s t r}$ is the instrumental correction and $\Delta \sigma_{0}^{\text {atmos }}$ is the atmospheric correction to $\sigma_{0}$ (identical at $\mathrm{Ku}$ and $\mathrm{C}$ band).

As said earlier, the atmospheric correction is systematically subtracted from the $\sigma_{0}^{G D R}$. Thus, in the following, $\sigma_{0}$ measurements will always refer to $\sigma_{0}$ measurements with atmospheric corrections subtracted.

\subsubsection{Jason Altimeter}

Figure 1 and Table 1 present the statistical analysis of 20 Topex/Jason cycles (cycle 18 during which the Ku-band Poseidon-1 altimeter was operating on board Topex can not be used) of coincident and Jason $\sigma_{0}$ measurements (i.e. 4000000 samples). As the Jason instrumental correction includes a bias estimated by comparison of Topex and Jason $\sigma_{0}$, the mean $\mathrm{Ku}$ band $\sigma_{0}$ values are very close $(0.15 \mathrm{~dB}$ of difference). The correlation between the two data sets is over $99.5 \%$ and the statistical characteristics are very similar. No significant differences between the two sets can be detected. The $\sigma_{0}{ }^{K u}$ probability density functions (pdf) are also in good agreement. The distribution of the $\sigma_{0}{ }^{k u}$ difference is nearly Gaussian with a $0.15 \mathrm{~dB}$ mean and a standard deviation of $0.13 \mathrm{~dB}$, i.e. close to the precision of the $\sigma_{0}$ 
measurements.

The C-band $\sigma_{0}$ statitistical analysis gives similar results. The correlation is $99.7 \%$ and the bias is about $0.45 \mathrm{~dB}$. The standard deviation is very similar for the two sensors and no significant differences can be pointed out. The $\sigma_{0}$ pdf's are in good agreement, the Jason one being smoother than the Topex one because of a better digitisation of the signal. The $\sigma_{0}$ difference pdf is nearly Gaussian with a standard deviation of $0.11 \mathrm{~dB}$. As fewer instrumental corrections are applied to the $\sigma_{0}{ }^{c}$, especially on the Topex data, the standard deviation of the difference is smaller at $\mathrm{C}$ band than at $\mathrm{Ku}$ band (see figure 1).

This overall statistical analysis of the coincident $\sigma_{0}$ Topex and Jason data shows a good agreement between the two sensors and does not reveal any significant differences other than the natural geophysical and instrumental variability.

The eventuality of $\sigma_{0}$ drift has also been investigated using a (Jason) cycle-by-cycle statistical analysis of the coincident data sets. Figure 2 presents the mean and standard deviation of the $\Delta \sigma_{0}$ at $\mathrm{Ku}$ and $\mathrm{C}$ band as a function of Jason cycle number. For a better reading the overall mean and standard deviation have been removed. The mean values are around $0.15 \mathrm{~dB}$ and $0.45 \mathrm{~dB}$ and vary only $\pm 0.05 \mathrm{~dB}$. The standard deviations are almost constant at $0.15 \mathrm{~dB}$ and $0.12 \mathrm{~dB}$. No drift can be detected for the first 22 Jason cycles.

To further compare the $\sigma_{0}$ data set, a regression analysis has also been conducted to compare the dynamics of the $\sigma_{0}$ measurements. The regression of the Jason versus Topex $\sigma_{0}$ shows that Jason tends to slightly overestimate high $\sigma_{0}$. The slope of the regression line is about 1.015 and the standard deviation is $0.15 \mathrm{~dB}$. At $\mathrm{C}$ band, the $\sigma_{0}$ are in better agreement and the slope of the regression line is almost unity (0.999). The dispersion around the relation is $0.12 \mathrm{~dB}$. Similar results have been found for each Jason cycles and the slopes of the regression remain very stable from cycle to cycle (see figure 3).

The overall $\sigma_{0}$ analysis shows that once the atmospheric corrections removed the Jason and Topex $\mathrm{Ku}$ and $\mathrm{C} \sigma_{0}$ backscatter data give similar information. The cycle-by-cycle analysis 
did not reveal any drift in the sensors during the first 6 months of Jason operation.

\subsubsection{Envisat}

Figure 3 presents the distributions of the $\mathrm{Ku}$ and $\mathrm{S}$ band ( 350000 samples used) for cycle 11 and 12 (November and December 2002). The Envisat Ku band pdf has a similar shape to the $\mathrm{Ku}$ band Topex and Jason ones. The mean value $(10.90 \mathrm{~dB})$ is slightly lower than the Jason one whilst the standard deviation $(1.52 \mathrm{~dB})$ is larger than the Topex and Jason ones (see Table 1). The pdf is more dissymmetric than the Jason one and presents slight bumps near 10 $\mathrm{dB}$ and $11.5 \mathrm{~dB}$. No explanation has yet been found for this feature.

The $\mathrm{S}$ band $\sigma_{0}$ distribution is quite similar to the $\mathrm{C}$ band $\sigma_{0}$ Topex and Jason distributions. The standard deviation is similar to the $\mathrm{Ku}$ one and somewhat larger than the Topex and Jason $\mathrm{C}$ band one.

For the November and December period, the Envisat data have been systematically collocated with the Jason and Topex measurements. The collocation limits were set to 20 min in time and $50 \mathrm{~km}$ in space. About 1682 collocations with Jason and 2344 with Topex were found. The correlations between the Envisat and the Topex and Jason $\sigma_{0}{ }^{K u}$ are respectively $98 \%$ and $97 \%$. For the $\sigma_{0}{ }^{s}$ the correlation is $98 \%$ with both the Topex and Jason $\sigma_{0}{ }^{\mathrm{C}}$. The mean biases are respectively $-0.49 \mathrm{~dB}$ and $-0.61 \mathrm{~dB}$ for $\mathrm{Ku}$ band and $-4.43 \mathrm{~dB}$ and $4.78 \mathrm{~dB}$ for $\mathrm{C} / \mathrm{S}$ band. The standard deviation of the $\sigma_{0}$ difference for both altimeters and band is about $0.3 \mathrm{~dB}$ (see Figure 4). Considering the time and space separation of the samples, this reflects a good agreement of the $\sigma_{0}$ measurements.

The collocated data sets analysis shows that except for a constant bias the Envisat Ku and S band $\sigma_{0}$ data sets are in good agreement with the Topex and Jason $\mathrm{Ku}$ and $\mathrm{C}$ band $\sigma_{0}$ ones.

\subsection{Rain free dual frequency $\sigma_{0}$ relation}

The rain free dual frequency $\mathrm{Ku} / \mathrm{C}(\mathrm{S})$ band $\sigma_{0}$ relation is obtained by binning the $\mathrm{Ku}$-band $\sigma_{0}$ data in intervals of $0.1 \mathrm{~dB}$ of $\sigma_{0} \mathrm{C}$ or $\mathrm{S}$ band. The mean, $f\left(\sigma_{0}^{S / C}\right)$, and standard deviation, 
$r m s\left(\sigma_{0}{ }^{s / c}\right)$, is then computed in each bin.

\subsubsection{Jason $\mathrm{Ku} / \mathrm{C}$ band relation}

The $f$ relations for Topex and Jason computed from the overall coincident data set are presented in Figure 5. For a better reading, they are presented as $f\left(\sigma_{0}{ }^{c}\right)-\sigma_{0}{ }^{c}$ in the figure. The bias between the Jason and Topex $\mathrm{C}$ and $\mathrm{Ku}$ band $\sigma_{0}$ clearly appears on the $f$ relation. However, once the bias removed from both $\mathrm{Ku}$ and $\mathrm{C}$ band Topex $\sigma_{0}$, the two relations are almost identical up to $\sigma_{0}{ }^{c}=16 \mathrm{~dB}$ (i.e. for $90 \%$ of the data). The difference between the two relations is almost constant at $0.05 \mathrm{~dB}$. For $\sigma_{0}{ }^{c}$ above $16 \mathrm{~dB}$, the difference increases reaching a maximum of $0.2 \mathrm{~dB}$ for $\sigma_{0}{ }^{c}=18 \mathrm{~dB}$. This difference results from the slight overestimation of high $\sigma_{0}$ by Poseidon 2 compared to Topex. For very high $\sigma_{0},(>20 \mathrm{~dB})$, the relation has less significance as there are few points in each bin and as the natural $\sigma_{0}$ variability is high. For comparison, the difference between the Topex relation and the standard relation given prior to launch has also been plotted on the figure. The difference is almost constant at $0.025 \mathrm{~dB}$ which shows the good stability of the Topex relation over time.

The rms around the $\mathrm{Ku} / \mathrm{C}$ relation is another important feature of the rain flag definition. The Jason rms is smaller than the Topex ones (by $0.03 \mathrm{~dB}$ to $0.1 \mathrm{~dB}$ ). The Topex rms is similar to the rms of the prelaunch Topex relation. The smaller value of the rms for Jason certainly reflects the better quality of the new sensor.

There is a very good agreement of the $f$ relations for medium and high winds. For low winds (high $\sigma_{0}$ ), the difference is noticeable. The rms is significantly smaller for Jason over the whole $\sigma_{0}$ range. The main parameter used in the rain flagging process is however the normalized departure, $\Delta \sigma_{0}{ }^{N}=\left(\sigma_{0}{ }^{k u}-f\left(\sigma_{0}{ }^{C}\right)\right) / r m s\left(\sigma_{0}{ }^{c}\right)$, from the $f$ relation. The pdf's of the normalized departure, presented in Figure 6, are very similar for Jason and Topex. The concordance of the two curves is especially good for $\Delta \sigma_{0}{ }^{N}<-2$.

The comparison of the Topex and Jason $\mathrm{Ku} / \mathrm{C}$ band relation is good and from a statistical point of view no difference can be detected in the detection of departure from the $\mathrm{Ku} / \mathrm{C}$ band 
relation.

The temporal evolution of the $f$ relation has also been investigated. Apart from the natural variability no trends or drift were detected.

\subsection{Envisat $K u / S$ band $\sigma_{0}$ relation}

In the same way as the Jason $\mathrm{Ku} / \mathrm{C}$ band relationship, the Envisat RA-2 $\mathrm{Ku} / \mathrm{S}$ band relationship and its rms are estimated by binning the $\mathrm{S}$ band and computing the mean and standard deviation of the corresponding $\sigma_{0}{ }^{K u}$ values. The $f$ relation and its $r m s$ estimated from the November and December 2002 RA-2 data set is presented in Figure as well as the prelaunch theoretical relation and the Jason relation estimated for the same period. For a better comparison, the Jason relation has been shifted by $5 \mathrm{~dB}$ in $\mathrm{S}$ band and $1 \mathrm{~dB}$ in Ku band and the theoretical relation has been shifted of $4.3 \mathrm{~dB}$ in Ku band. For very low winds (high $\left.\sigma_{0}\right)$ the dispersion of the RA2 data is larger than those TOPEX and JASON. This larger dispersion might results from a different response of $\mathrm{S}$ and $\mathrm{C}$ bands compared to $\mathrm{Ku}$ band for low winds.

The Envisat $f$ relation has also been compared to the Jason and Topex using the collocated data sets. The biases $\mathrm{Ku}$ and $\mathrm{C}$ band between the sensors are subtracted to allow a better comparison. The $f$ relations for the different altimeters, presented in figure 8 , are very similar considering the limited size of the collocated data sets.

The pdf of the departure and normalized departure from the $f$ relation is given in figure 9 as well as the Jason one. The agreement between the two curves is very good especially in the rain flagging part of the pdf (normalized departure less than -2).

\section{RAIN FLAGGING}

\subsection{Jason}

The next step in the rain flag validation process is to test the rain flagging itself using the mean relation defined in the previous sections. The rain flagging uses two criteria; the first one detects occurrences for which the $\sigma_{0}{ }^{K u}$ is significantly attenuated compared to the value that can be expected from the $\mathrm{C}$ band measurements and the second one, especially necessary 
at low wind speed, insures the presence of cloud liquid water within the atmosphere using the passive microwave radiometer liquid water estimates.

The validation of the cloud liquid water estimate from JMR is beyond the scope of the present study, but it is an important component of the rain flag. In order to avoid any $L_{z}$ calibration problems, the rain flagging is tested using both Topex and Jason $L_{z}$ estimates for the second criterion.

During the calibration-validation period, Poseidon-2 experienced some $\sigma_{0}{ }^{K u}$ drift which lead to erroneous rain flagging. After checking by CNES, it appeared that these drifts were associated with satellite manoeuvres that were not perfectly screened off by instrumental flags. The days when such events occurred were removed from the rain flag validation data set. As we want to test the rain flagging the data screening criteria are changed in the following way: the liquid water content test is removed and the off-nadir angle limit is set to $0.25 \mathrm{deg}$ for Topex and $0.06 \mathrm{deg}^{2}$ for Jason. The number of samples that fails the $\sigma_{0}$ criterion alone is 73452 for Jason and 89034 for Topex. These numbers are reduced to 49131 and 43560 respectively using the Jason Microwave Radiometer (JMR) $L_{z}$ estimate for the second criterion, and to 55976 and 54433 respectively fusing Topex Microwave Radiometer $L_{z}$. Except for Topex and JMR the numbers are very similar. The independent rain flags, i.e. Jason and JMR and Topex and TMR give very similar figures. It should be noted that when considering the rain flagged samples, the $\Delta \sigma_{0}{ }^{K u}$ standard deviation between collocated samples increase to about $0.22 \mathrm{~dB}$ whilst the $\Delta \sigma_{0}{ }^{C}$ remains at about $0.14 \mathrm{~dB}$. The attenuation of the signal by rain and the small scale of the rain events; $40-50 \%$ of the flagged samples are isolated ones corresponding to a rain cell length of $5 \mathrm{~km}$ or less; induce a higher $\sigma_{0}$ variability at $\mathrm{Ku}$ band. This variability explains why rain flagging can present a significant variability between the sensors even for a mean separation of collocated samples of about 3 $\mathrm{km}$.

The latitudinal distributions of the number of flagged samples, presented in figure 10, show a very good agreement between the 4 distributions. The major differences occur for Topex 
and JMR in the equatorial region and for Topex and TMR at high southern latitude. The number of samples flagged by Jason/JMR and Topex/TMR does not presents significant difference except for high southern latitude $\left(<40^{\circ} \mathrm{S}\right)$. No complete explanation has yet been found. However, as this feature does appear when using JMR $L_{z}$, it might results from the drift observed and monitored on the TMR brightness temperature measurements.

The rain flagging has then been applied independently to each altimeter, thus using JMR $L_{z}$ for Jason and TMR $L_{z}$ for Topex, and the mean distribution of the probability of rain, i.e. ratio of the number of flagged samples and of the total number of samples, has been estimated. The mean rain probability fields are presented in Figure 11. They have similar values and patterns and the difference between the two fields is, except for some regions near the coasts and in the southern ocean within $+0.005(0.5 \%)$. Jason tends to flag slightly more samples in the Tropics whilst Topex flags more samples in the southern ocean.

This analysis shows that the Jason rain flag has almost identical performances as the Topex one.

\subsection{Envisat}

A direct comparison of the rain flagging between Envisat and Topex/Jason is not possible because of the limited size of the collocated data sets. The validation of the rain flag depends thus on statistical comparison of the rain flagging results for the November-December 2002 period. We used the Jason Poseidon-2 and JMR data and the Envisat RA-2 and Microwave Radiometer (MWR) data. The geographical distribution of the probability of rain-flagged samples for the November-December period is presented in figure 12 for both altimeters. Considering the strong natural rain variability, the important difference of time and space sampling of the ocean by the two altimeters (10 day repeat period for Jason and 35 day for Envisat), and the non intercalibration of the $L_{z}$ estimates for the two altimeters, a two month period is certainly not enough for a statistical comparison. However, the two fields present very similar features and probability levels, except for high northern latitudes where Envisat flags more samples near Japan and the USA West coast. The latitudinal distribution of the flagged samples shows a very good agreement for latitude less than $35^{\circ} \mathrm{N}$. 


\section{COMPARISON WITH GPCP CLIMATOLOGY}

As a final validation for Jason, the rain flagging process was independently applied to cycles 2 to 27 for both Jason and Topex, i.e. using all available data and not only the collocated ones. JMR $L_{z}$ was used for Jason and TMR $L_{z}$ for Topex for the second criterion. For each of the rain-flagged samples, an estimate of rain rate was estimated by (Tournadre and Morland, 1998)

$$
R=\frac{\left(-\Delta \sigma_{o}\right)^{1 / b}}{-2 H a}
$$

where $a$ and $b$ are the coefficients of the Marshall-Palmer relation for Ku band (3.46 10-2 and 1.109) $H$ the rain height (fixed to $5 \mathrm{~km}$ ) and $\Delta \sigma_{0}$ the $\mathrm{Ku}$ band attenuation.

The rain estimates are then averaged over a $5^{\circ}$ latitude longitude grid and the resulting field is multiplied by the rain probability to get a mean rain rate. Figure 13 presents the comparison of the February 2002 to August 2002 period mean rain rate field estimated for Jason and Topex and from the Global Precipitation Climatology Project (GPCP) monthly fields combining satellite and rain gage data http://precip.gsfc.nasa.gov/. As more studies are needed to inter-calibrate the different rain rate estimated the fields presented in the figure have be normalized by the maximum values. The GPCP fields have been resampled at the same resolution than the altimeter fields.

There is a very good agreement between the Jason, Topex and GPCP rain patterns, especially in the tropical regions. For higher latitude the altimeter mean rain rate estimated by relation (4) is underestimated mainly because $5 \mathrm{~km}$ is used as freezing level (H) is too high for high latitudes. The Jason rain rate estimates are in better agreement with the GPCP ones than the Topex ones except for the southern latitudes.

\section{CONCLUSION}

The analysis of coincident Topex and Jason data during the cycles 2 to 22 shows that there is a very good agreement between the two altimeters for the backscatter measurements in $\mathrm{Ku}$ and $\mathrm{C}$ bands, except for a bias almost constant in time. The analysis of the Envisat backscatter data at $\mathrm{Ku}$ and $\mathrm{S}$ band also shows a good agreement when using ensemble and 
collocated data sets. The Topex and Jason $\mathrm{Ku} / \mathrm{C}$ band $\sigma_{0}$ relation $(f)$ are very similar and no trend has been detected in the cycle-to-cycle analysis. The rms of the relation is higher for Topex than for Jason, resulting certainly from a better quality of the newest sensor. The Ku/S band Envisat relationship has also similar shape except for low wind speed. The rms is notably higher.

The comparison of the rain flagging shows that the Jason flag has similar, if not better performances than for Topex. The intercalibration of the Topex TMR and Jason TMR will certainly further improve the comparison between the two rain flags. The comparison with GPCP rain climatology shows good qualitative and quantitative agreement considering the difference of time and space sampling.

For Envisat a direct intercomparison of the rain flagging process is more difficult because of the strong difference in the sampling scheme and in the $L_{z}$ estimates. However the results shows that the flag performs satisfactorily.

The results, so far, show that the proposed rain flag can be operationally used with the mean $f$ relation and rms estimated from the first 27 cycles of Jason and the first 2 month of Envisat data. The percentage of flagged samples is of the same order of magnitude as the one found using the old one based on liquid water threshold. As for Topex, the behaviour of the $f$ relation should be carefully monitored during the satellite lifetime to assess the quality of the rain flagging process. 


\section{REFERENCES}

Benveniste J; Roca M; Levrini G; Vincent P; Baker S; Zanife O; Zelli C; Bombaci O, 2001, The Radar Altimetry mission: RA-2, MWR, DORIS and LRR, ESA Bullettin, 106, pp 67-76.

Elfouhaily T., D. Vandemark D., Gourrion J., and B. Chapron, 1998: Estimation of wind stress using dual-frequency TOPEX data, J. Geophys. Res., October 15, 103, 2510125108.

ENVISAT RA2/MWR Products Handbook, 2002, J. Benveniste Ed., PO-TN-ESR6RA-0050, European Space Agency, ESRIN, Frascati, Italy.

Guymer, T.H., Quartly, G.D., and M.A. Srokosz, 1995: The effect of rain on ERS-1 altimeter data, J. Atmos. Oceanic. Technol., 12, 1229-1247.

Marshall, J.S. and W. McK. Palmer, 1948: The distribution of rain drops with size, J. Meteor., 5, 165-166.Quartly, G.D., T.H. Guymer, and M.A. Srokosz, 1996: The effects of rain on Topex radar altimeter data, J. Atmos. Oceanic. Technol., 13, 1209-1229.

Ménard Y. And L. Fu, 2001, Jason-1 Mission, Aviso Newsletter ,8, Aviso Altimetry Edition.

Quartly G.D., Guymer T.H. and Srokosz M.A. 1996, 'The Effects of Rain on Topex radar altimeter data, J. Atmos. Oceanic. Tech., 13, 1209-1229.

Quartly, Graham D., 1998: Determination of Oceanic Rain Rate and Rain Cell Structure from Altimeter Waveform Data. Part I: Theory. J.Atmos. Oceanic. Technol., 15, 13611378.

Quartly G.D., M.A. Srokosz and T.H. Guymer, 1999, Global precipitation statistics from dual-frequency TOPEX altimetry, J. Geophys. Res. 104, 31489-31516.

Resti A; Benveniste J; Roca M; Levrini G; Johannessen J, 1999, The Envisat Radar Altimeter system (RA-2), ESA Bulletin, 98, pp 94-101.

Ruf, C., S.J. Keihm and M.A. Janssen, 1995, TOPEX/Poseidon Microwave Radiometer (TMR): I Instrument description and antenna temperature calibration, IEEE Trans. Geosci. Remote Sensing, 33, 125-137.

SSALTO, 1999, Algorithm definition accuracy and specification, Volume 2, CMA altimeter level 1B processing, Centre National d'Etudes Spatiale, Toulouse, France, SMM-STM2-EA-11003-CN.

Tournadre, J. and J.C. Morland, 1997: The effect of rain on Topex/Poseidon altimeter data: a new rain flag based on $\mathrm{Ku}$ and $\mathrm{C}$ band backscatter coefficients, IEEE Trans. Geosci. Remote Sensin., 35, 1117-1135.

Tournadre, Jean, 1998: Determination of Rain Cell Characteristics from the Analysis of TOPEX Altimeter Echo Waveforms, J. Atmos.Oceanic. Technol., 15, 387-406.

Tournadre J., G. Quartly, and M. Srokosz , 2000 : Analysis of the effect of rain on the Envisat altimeter: definition of a rain flag. Proc. ERS/ENVISAT SYMPOSIUM 2000, 16-20 October 2000, Göteborg, Sweden , ESA- SP-461

Tournadre J., and G. Quartly, 2003 : Validation of Envisat RA2 rain flag, Tech. Report IFREMER, DRO-OS 03-01, Ifremer, BP 70 29280, Plouzane, France.

Ulaby, F. T., R. K. Moore, and A. K. Fung, 1981: Microwave remote sensing: active and passive, Vol.I, Addison-Wesley Publ. Comp., Reading, Massachusetts. 


\begin{tabular}{|l|c|c|c|c|c|}
\hline \multirow{2}{*}{ Data set } & \multirow{2}{*}{ Number } & \multicolumn{2}{c|}{ Ku } & \multicolumn{2}{c|}{ C (S for } \\
\cline { 3 - 6 } & Mean & Std & Mean & Std \\
\hline Jason & 4000000 & 11.26 & 1.22 & 14.72 & 1.22 \\
\hline Topex & 4000000 & 11.42 & 1.25 & 15.16 & 1.22 \\
\hline Envisat & 450000 & 10.90 & 1.52 & 10.45 & 1.62 \\
\hline Jason/Topex & 4000000 & 0.15 & 0.13 & 0.45 & 0.11 \\
\hline Envisat-Jason & 1682 & -0.61 & 0.31 & -4.78 & 0.37 \\
\hline Envisat-Topex & 2344 & -0.49 & 0.28 & -4.43 & 0.33 \\
\hline
\end{tabular}

Table 1: Statistical characteristics, mean, standard deviation of Jason, Topex and Envisat Ku, $\mathrm{C}$ and $\mathrm{S}$ band $\sigma_{0}$ data sets and of the $\Delta \sigma_{0}$ data sets of the collocated samples 


\section{Figure CAPTIONS}

Figure 1: Probability density function of $\sigma_{0}$ measurements for Jason (solid lines) and Topex (dashed lines) at $\mathrm{Ku}$ band (a) and at $\mathrm{C}$ band (b). Pdf of $\Delta \sigma_{0}$ (Jason -Topex) at Ku band (c) and $\mathrm{C}$ band (d). Pdf of instrumental corrections at Ku band (e) and $\mathrm{C}$ band (f).

Figure 2: Evolution of the mean $\Delta \sigma_{0}$ and rms for Ku band (a) and $\mathrm{C}$ band (b) between Jason and Topex collocated data as a function of the Jason cycle number. The overall mean $\Delta \sigma_{0}$ $(0.15 \mathrm{~dB}$ and $0.45 \mathrm{~dB}$ at $\mathrm{Ku}$ and $\mathrm{C}$ bands $)$ and $\mathrm{rms}(0.13 \mathrm{~dB}$ and $0.11 \mathrm{~dB})$ has been subtracted for a better comparison. (c) Temporal evolution of the slope of the regression of Jason $\sigma_{0}$ versus Topex $\sigma_{0}$. The crosses denote the $\mathrm{Ku}$ band and the stars the $\mathrm{C}$ band.

Figure 3: Probability density functions of the Envisat (solid lines) $\sigma_{0}$ at $\mathrm{Ku}$ band (a) and $\mathrm{S}$ band (b). The Jason pdf of figure 1 has also been plotted as dashed line with the mean bias subtracted.

Figure 4: Probability density functions of the $\Delta \sigma_{0}$ between Envisat and Jason (solid line) and Topex (dashed line) for the collocated data sets at Ku band (a) and C/S band (b).

Figure 5: (a) $\mathrm{Ku} / \mathrm{C}$ band $\sigma_{0} f$ relationships; Jason: solid line; Topex relationship: dashed line; Topex with mean biases subtracted from the $\mathrm{Ku}$ and $\mathrm{C}$ band $\sigma_{0}$, small circles; Topex prelaunch standard relationship (note that it superposes the Topex relation up to $20 \mathrm{~dB}$ ), small crosses. (b) Difference between Jason and Topex relationship with biases removed relationships: solid line, difference between Topex and Topex standard relationships: dashed lines. (c) Same as 5-a for the $\mathrm{Ku} / \mathrm{C}$ band relationship rms, (d) same as 5-b for the relationship rms.

Figure 6: Probability density function of the Topex (dashed line) and Jason (solid line) normalized departure from the $f$ relation of figure 5. The shaded area represents the region of strong Ku band attenuation (criterion (1)).

Figure 7: (a) $\mathrm{Ku} / \mathrm{S}(\mathrm{C})$ band $\sigma_{0} f$ relationships; Envisat: solid line; Jason relationship (biases 
removed in $\mathrm{Ku}$ and $\mathrm{C}$ band): dashed line; Prelaunch theoretical relation, small crosses. (b) Same as 7 -a for the relationship rms.

Figure 8: Analysis of collocated Envisat and Jason/Topex data sets. (a) Envisat (solid line) and Jason (dashed line) f relation, (b) rms of the relations. (c) Envisat (solid line) and Topex (dashed line) f relation, (b) rms of the relations.

Figure 9: Probability density function of the Envisat (solid line) and Jason (dashed line) normalized departure from the $f$ relation of figure 7. The shaded area represents the region of strong Ku band attenuation.

Figure 10: Latitudinal distribution of the number rain flagged samples for Jason and Topex using the JMR or TMR $L_{z}$ estimate. JMR; Jason triangles; Topex pentagrams; TMR; Jason pluses; Topex, stars.

Figure 11: Comparison of Jason and Topex mean rain probability for Jason cycles 2 to 27.

(a) Jason, (b) Topex, (c) difference between Jason and Topex.

Figure 12: Comparison of the Envisat (a) and Jason (b) rain probability for NovemberDecember 2002. Comparison of the latitudinal distribution of the rain probability (c), Envisat, solid line; Jason, dashed line.

Figure 13 : Comparison of mean rain rate fields for February to August 2002 for (a) Jason (b) Topex (c) GPCP rain climatology. Each field is normalised by the maximum rain rate value. 

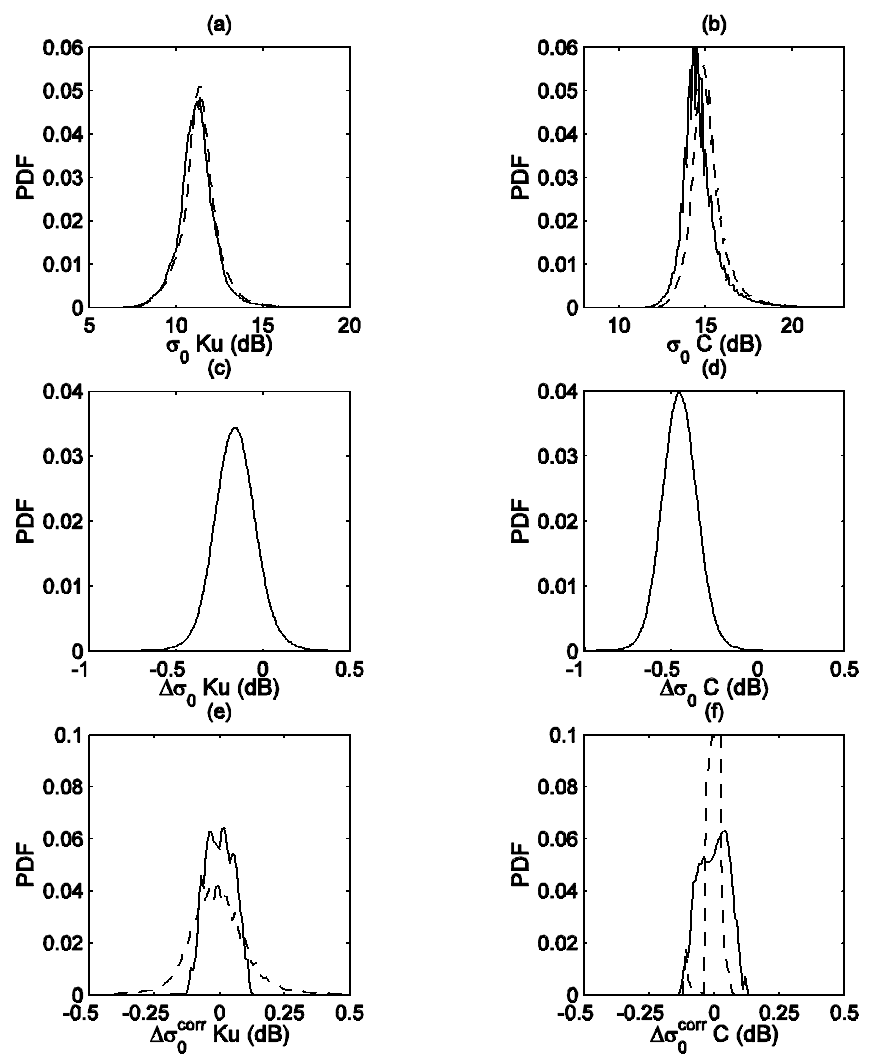

Figure 1: Probability density function of $\sigma_{0}$ measurements for Jason (solid lines) and Topex (dashed lines) at $\mathrm{Ku}$ band (a) and at $\mathrm{C}$ band (b). Pdf of $\Delta \sigma_{0}$ (Jason -Topex) at Ku band (c) and $\mathrm{C}$ band (d). Pdf of instrumental corrections at Ku band (e) and $\mathrm{C}$ band (f). 

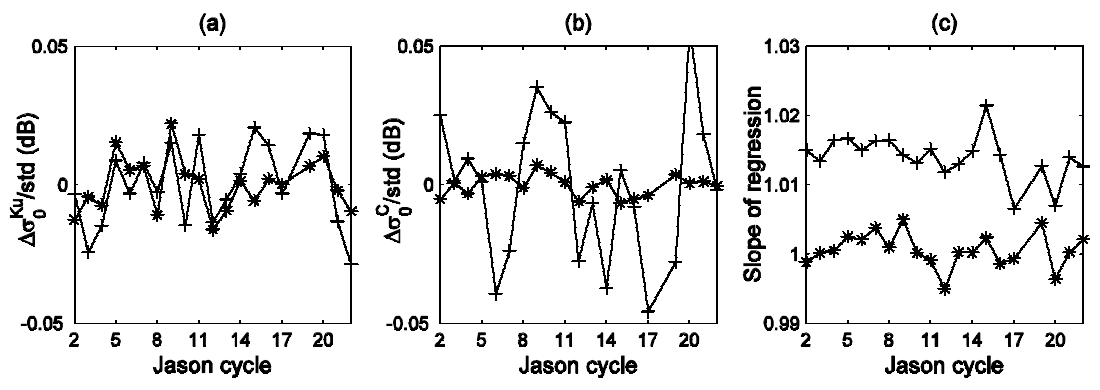

Figure 2: Evolution of the mean $\Delta \sigma_{0}$ and rms for Ku band (a) and $\mathrm{C}$ band (b) between Jason and Topex collocated data as a function of the Jason cycle number. The overall mean $\Delta \sigma_{0}$ $(0.15 \mathrm{~dB}$ and $0.45 \mathrm{~dB}$ at $\mathrm{Ku}$ and $\mathrm{C}$ bands $)$ and $\mathrm{rms}(0.13 \mathrm{~dB}$ and $0.11 \mathrm{~dB})$ has been subtracted for a better comparison. (c) Temporal evolution of the slope of the regression of Jason $\sigma_{0}$ versus Topex $\sigma_{0}$. The crosses denote the $\mathrm{Ku}$ band and the stars the $\mathrm{C}$ band. 
(a)

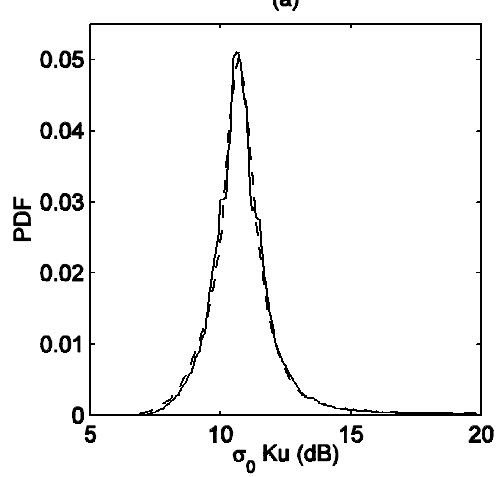

(b)

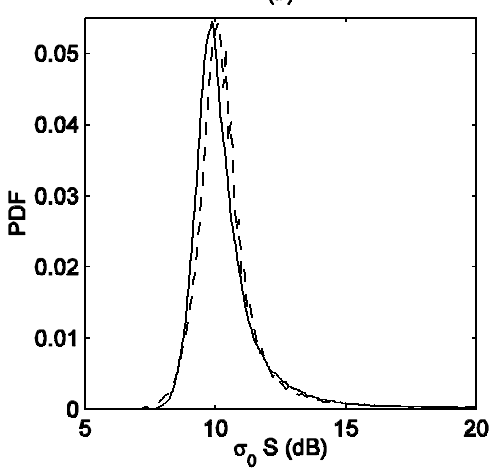

Figure 3: Probability density functions of the Envisat (solid lines) $\sigma_{0}$ at $\mathrm{Ku}$ band (a) and $\mathrm{S}$ band (b). The Jason pdf of figure 1 has also been plotted as dashed line with the mean bias subtracted. 
(a)

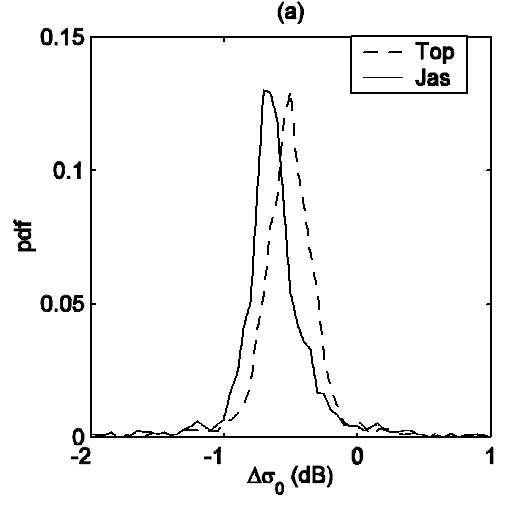

(b)

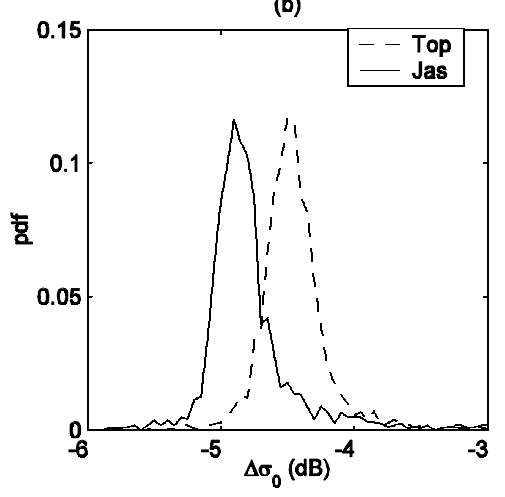

Figure 4: Probability density functions of the $\Delta \sigma_{0}$ between Envisat and Jason (solid line) and

Topex (dashed line) for the collocated data sets at Ku band (a) and C/S band (b). 

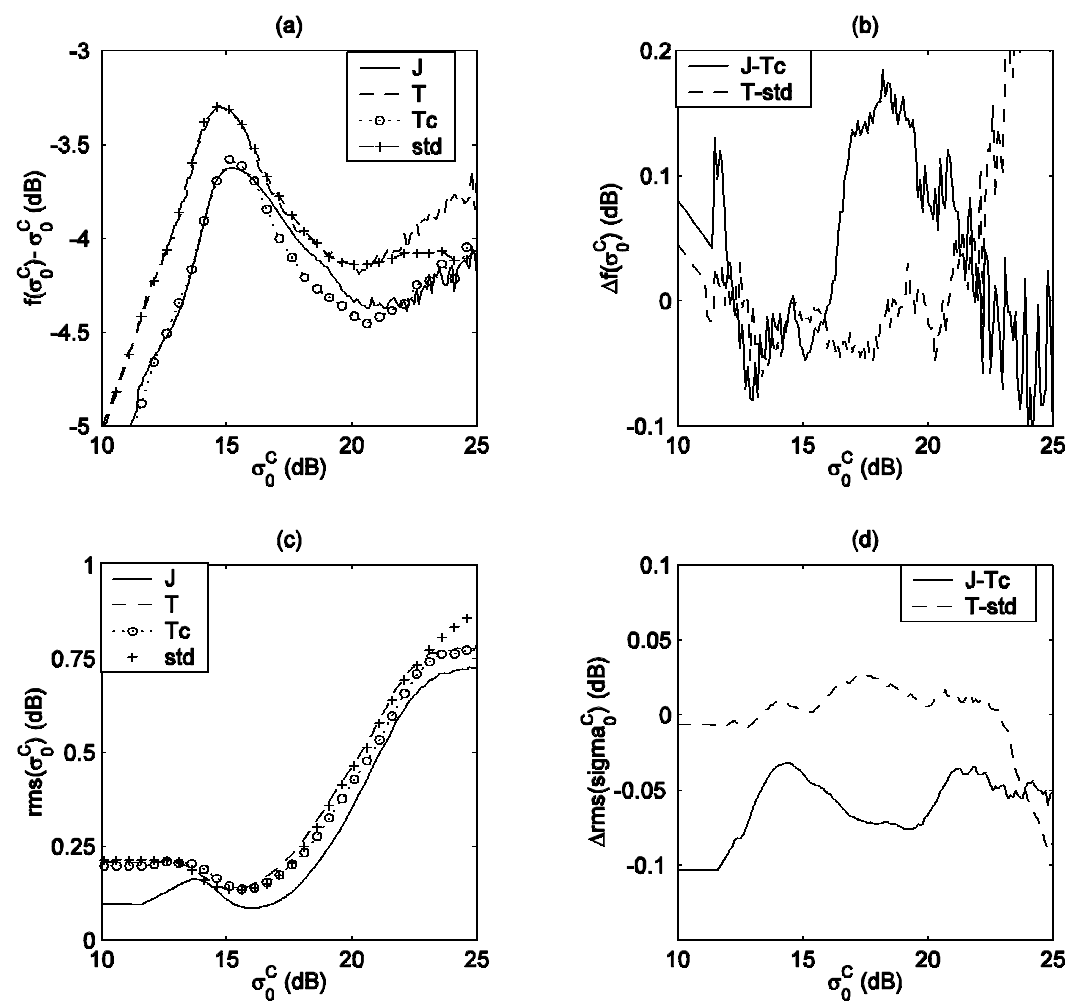

Figure 5: (a) $\mathrm{Ku} / \mathrm{C}$ band $\sigma_{0} f$ relationships; Jason: solid line; Topex relationship: dashed line; Topex with mean biases subtracted from the $\mathrm{Ku}$ and $\mathrm{C}$ band $\sigma_{0}$, small circles; Topex prelaunch standard relationship (note that it superposes the Topex relation up to $20 \mathrm{~dB}$ ), small crosses. (b) Difference between Jason and Topex relationship with biases removed relationships: solid line, difference between Topex and Topex standard relationships: dashed lines. (c) Same as 5-a for the $\mathrm{Ku} / \mathrm{C}$ band relationship rms, (d) same as 5-b for the relationship rms. 


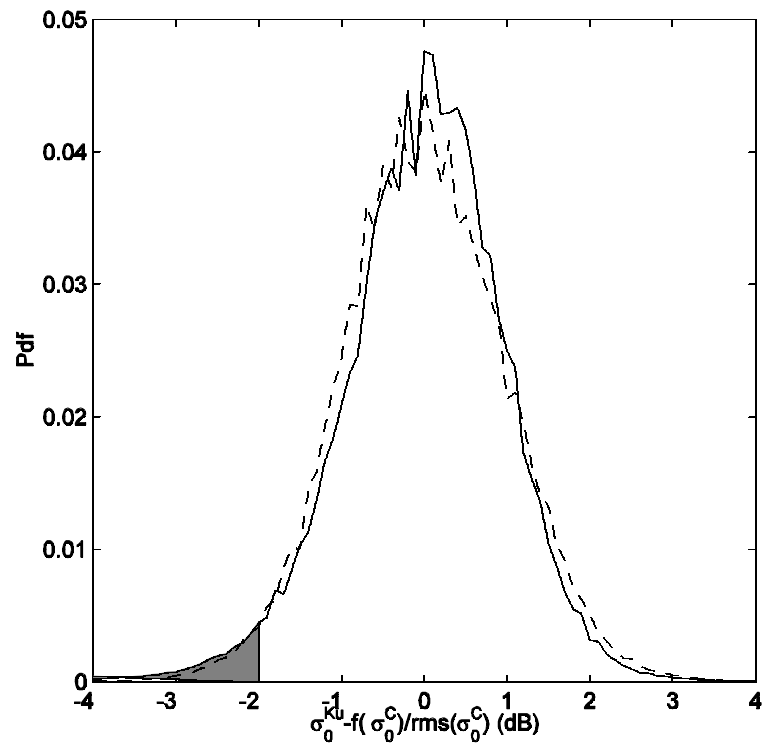

Figure 6: Probability density function of the Topex (dashed line) and Jason (solid line) normalized departure from the $f$ relation of figure 5. The shaded area represents the region of strong $\mathrm{Ku}$ band attenuation (criterion (1)). 
(a)

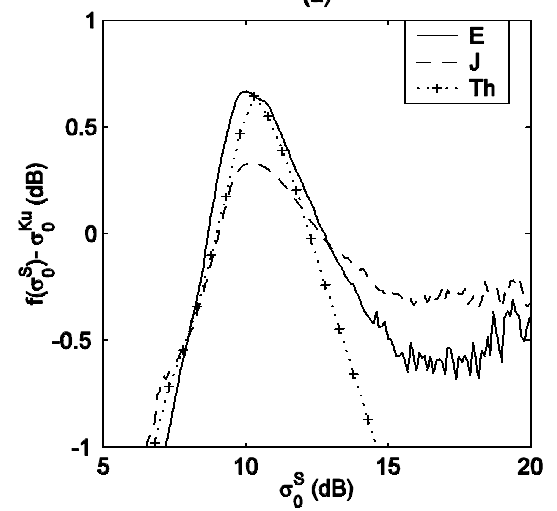

(b)

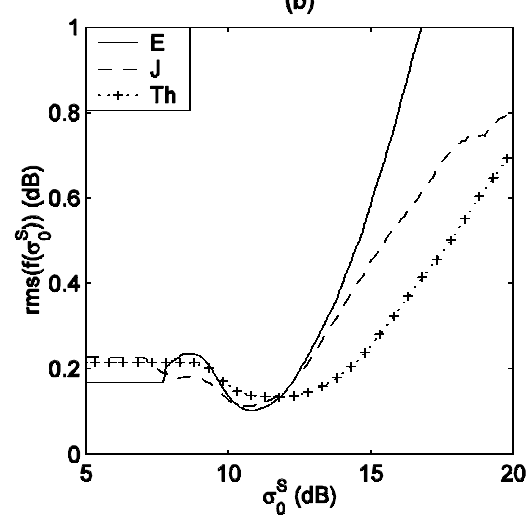

Figure 7: (a) $\mathrm{Ku} / \mathrm{S}(\mathrm{C})$ band $\sigma_{0} f$ relationships; Envisat: solid line; Jason relationship (biases removed in $\mathrm{Ku}$ and $\mathrm{C}$ band): dashed line; Prelaunch theoretical relation, small crosses. (b) Same as 7-a for the relationship rms. 
(a)
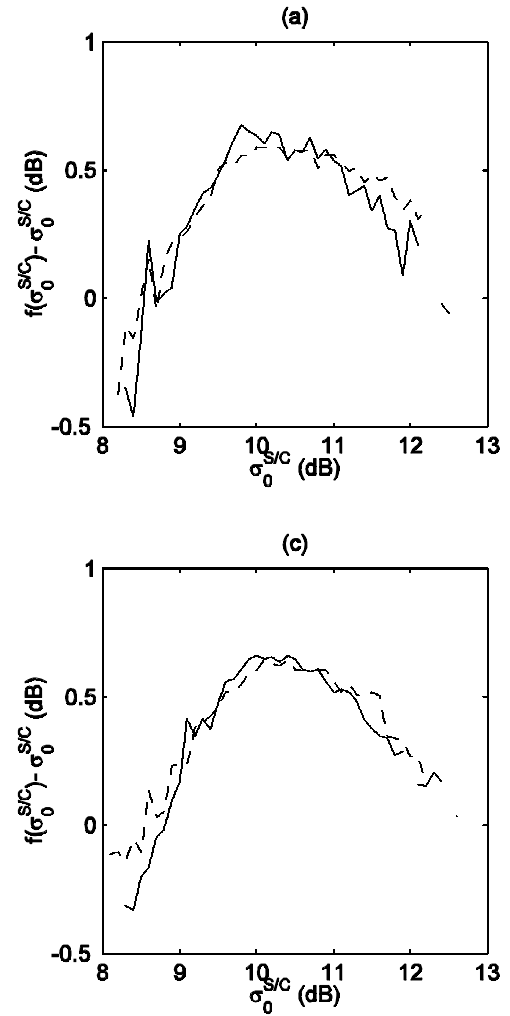

(b)

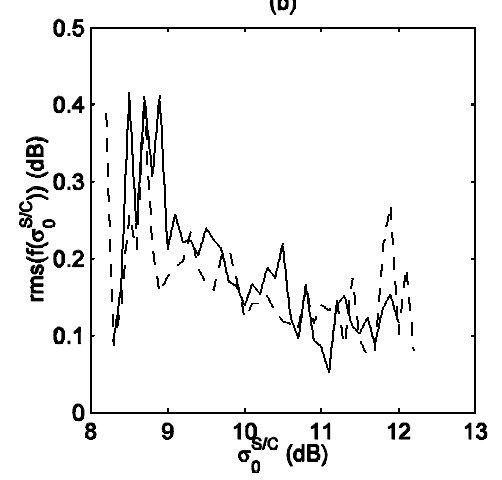

(d)

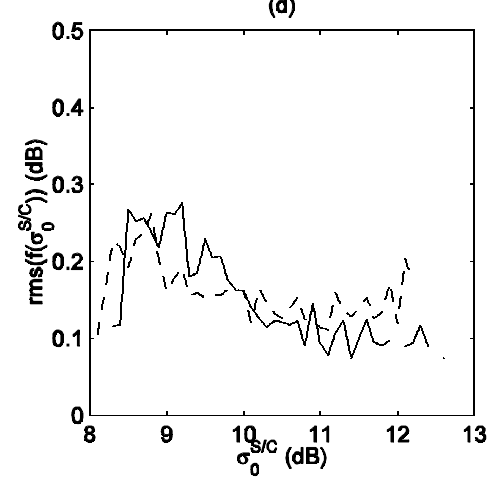

Figure 8: Analysis of collocated Envisat and Jason/Topex data sets. (a) Envisat (solid line) and Jason (dashed line) f relation, (b) rms of the relations. (c) Envisat (solid line) and Topex (dashed line) f relation, (b) rms of the relations. 


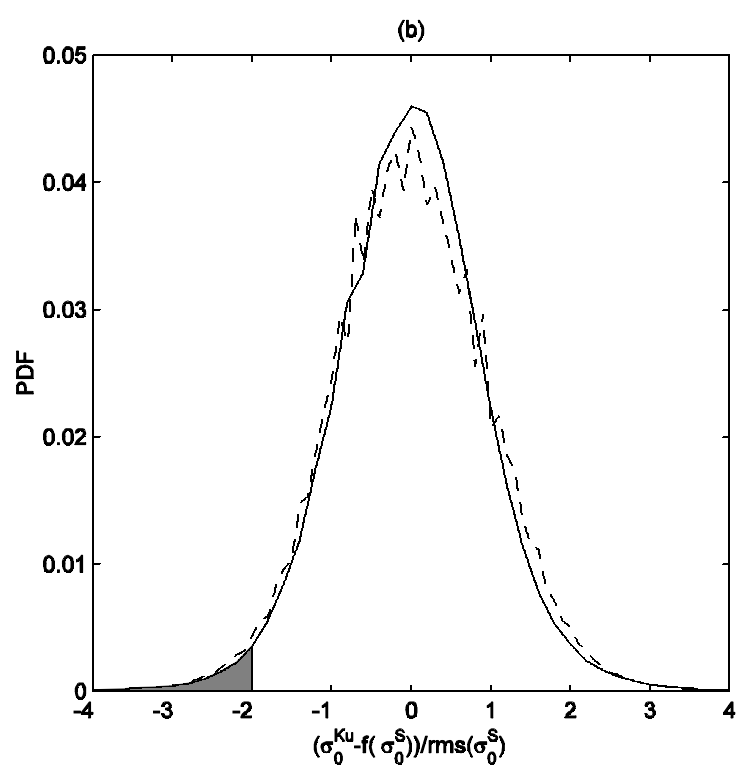

Figure 9: Probability density function of the Envisat (solid line) and Jason (dashed line) normalized departure from the $f$ relation of figure 7 . The shaded area represents the region of strong $\mathrm{Ku}$ band attenuation. 


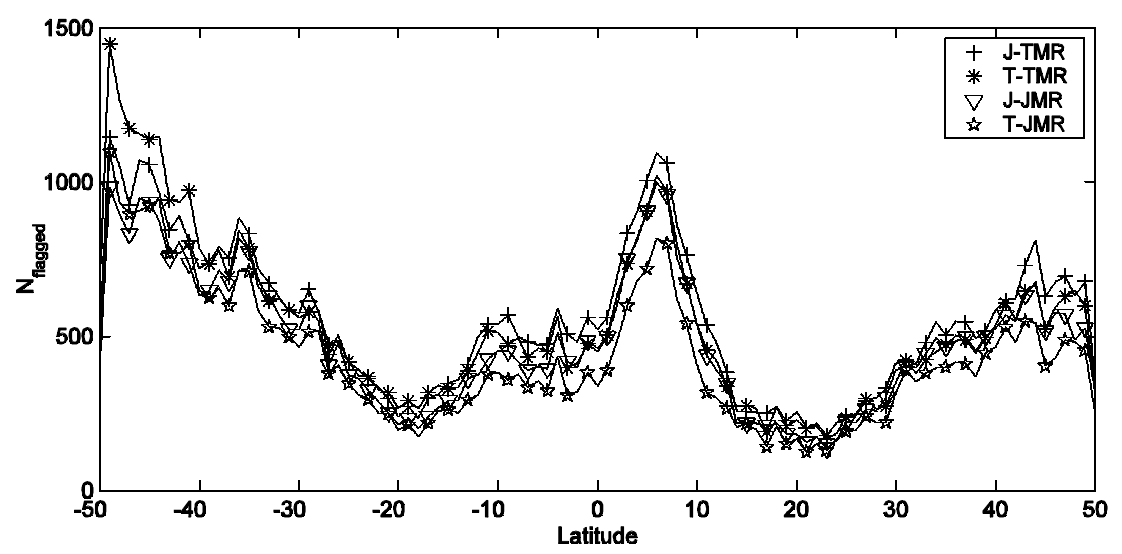

Figure 10: Latitudinal distribution of the number rain flagged samples for Jason and Topex using the JMR or TMR $L_{z}$ estimate. JMR; Jason triangles; Topex pentagrams; TMR; Jason pluses; Topex, stars. 


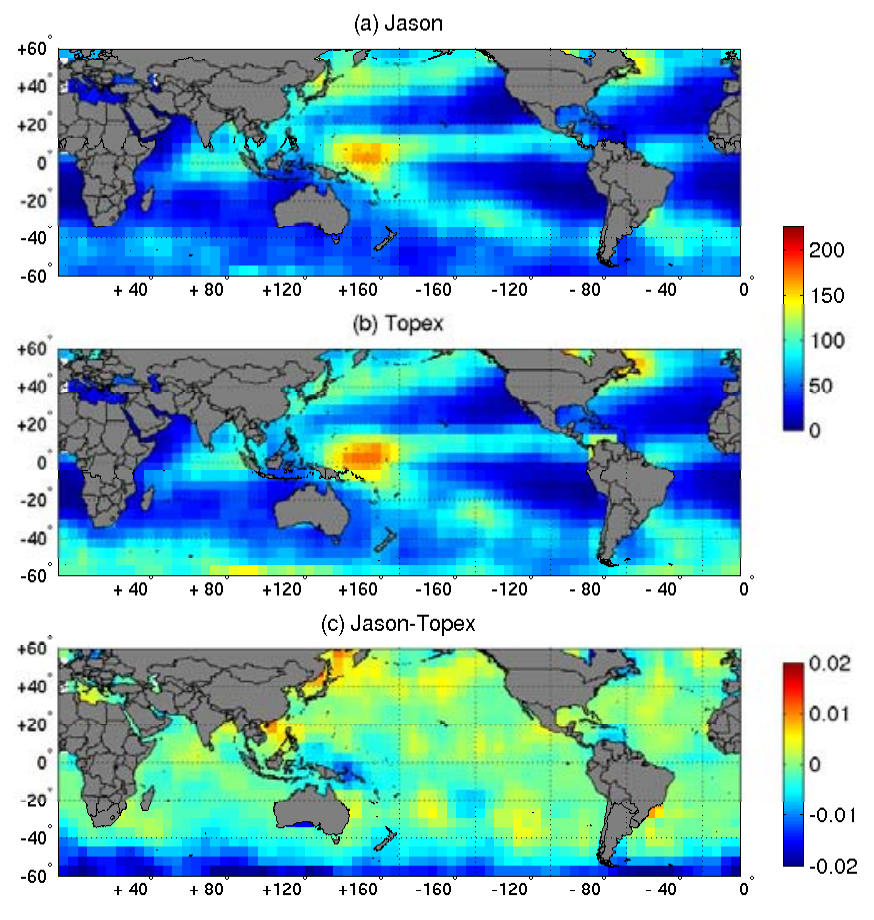

Figure 11: Comparison of Jason and Topex mean rain probability for Jason cycles 2 to 27.

(a) Jason, (b) Topex, (c) difference between Jason and Topex. 
(a)

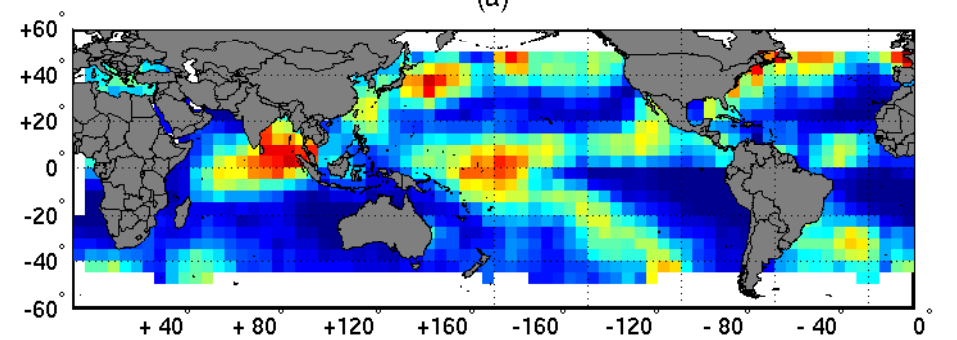

(b)

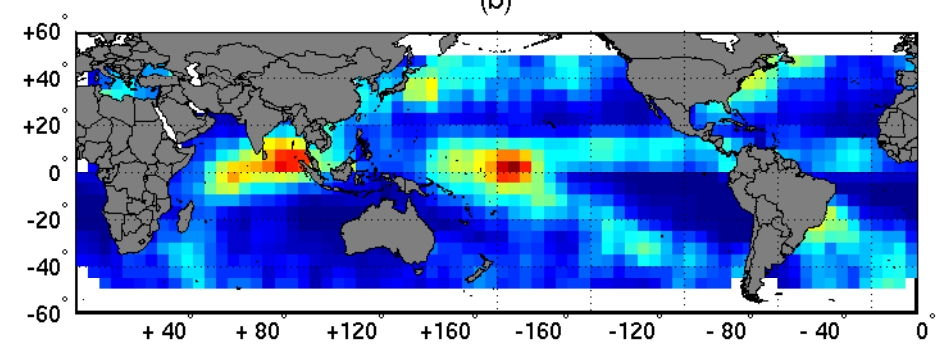

(c)

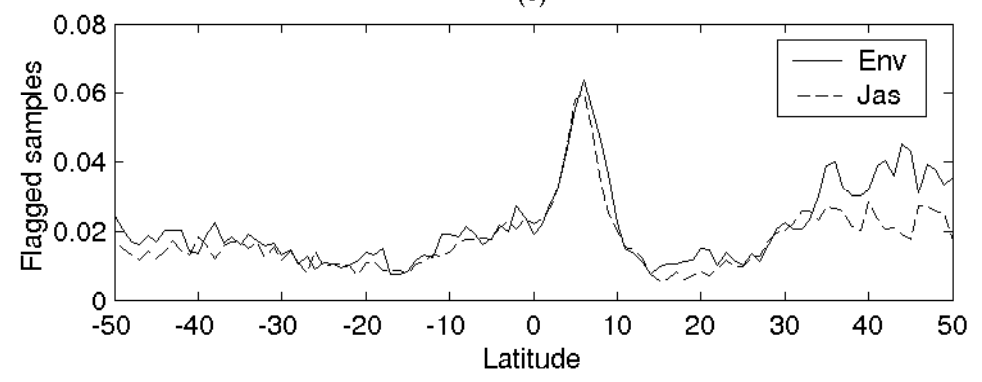

Figure 12: Comparison of the Envisat (a) and Jason (b) rain probability for NovemberDecember 2002. Comparison of the latitudinal distribution of the rain probability (c), Envisat, solid line; Jason, dashed line. 

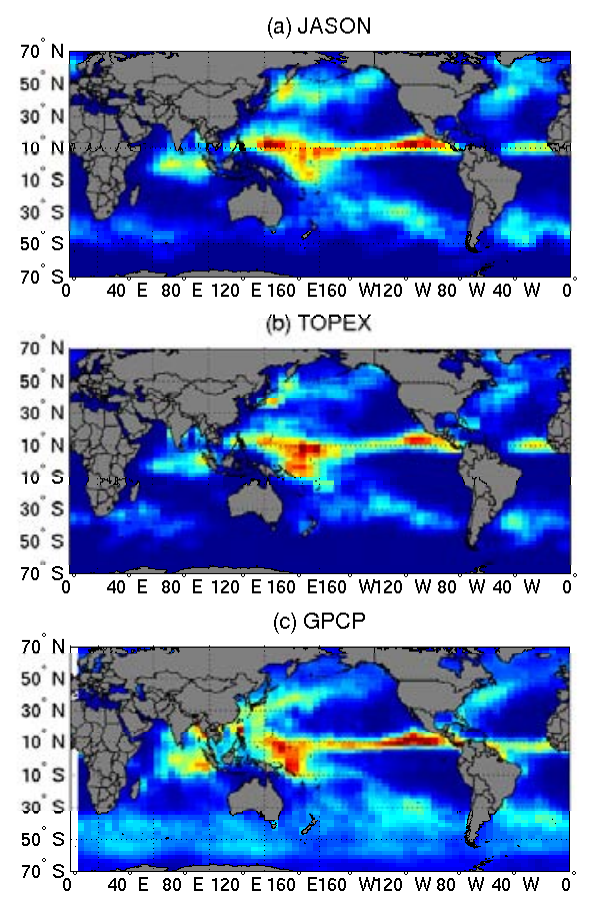

Figure 13 : Comparison of mean rain rate fields for February to August 2002 for (a) Jason (b)

Topex (c) GPCP rain climatology. Each field is normalised by the maximum rain rate value. 